\title{
O México como aliado dos EUA no projeto de integração das Américas
}

\author{
Mexico as an ally to the United States in the project for \\ integration of the Americas
}

MARCELO SANTOS*

Rev. Bras. Polít. Int. 50 (2): 146-161 [2007]

\section{Introdução}

Pode-se dizer que desde o lançamento do projeto "Iniciativa das Américas" pela administração George Bush em 1990 até os recentes impasses em torno das negociações da ALCA, os governos mexicanos vêm cumprindo um importante papel de aliado dos EUA no processo de integração econômica das Américas. A adesão incondicional ao modelo de integração previsto pelo Nafta e o empenho para consolidar os projetos do Corredor Biológico Mesoamericano e do Plano Puebla-Panamá são exemplos desse processo. Note-se que o projeto de integração previsto pelos EUA não é simplesmente a formação de uma área de livre comércio tradicional com a eliminação dos entraves ao trânsito de bens, mas, mais do que isso, ele prevê também a institucionalização de normas que garantam a liberalização comercial, financeira e dos investimentos de acordo com os interesses de seus grandes capitalistas, impedindo os demais países da região de modificarem suas políticas econômicas nacionais. Visto assim, esse projeto é uma tentativa de complementação e de consolidação jurídica do processo de reformas liberalizantes promovidas na América Latina nas duas últimas décadas sob monitoramento de Washington.

\section{O Nafta como modelo de integração subordinada}

A reestruturação econômica do México, via FMI e Banco Mundial, no contexto da crise da dívida na década de 1980, levou as elites governantes e dominantes desse país a iniciarem um amplo processo de liberalização econômica como parte de uma estratégia de crescimento econômico baseada nas exportações. Nas administrações de Miguel de La Madrid (1982-1988) e de

* Professor do Departamento de Antropologia, Política e Filosofia da Universidade Estadual Paulista-UNESP (Campus de Araraquara) e doutor em Ciências Sociais pela Universidade de Campinas - Unicamp (marsant28@yahoo.com.br). 
Carlos Salinas (1988-1994), o México entrou no GATT e avançou numa política de redução de tarifas alfandegárias e de acordos de livre comércio de tal forma que, quando começaram as negociações do Nafta, em 1989, o país já possuía uma economia bastante aberta. Nesse sentido, pode-se dizer que, para o México, a entrada em vigor do Nafta, em $1^{\circ}$ de janeiro de 1994 , fez parte do processo de reformas para o mercado que o país já vinha adotando em cumplicidade com os organismos financeiros internacionais e o tesouro dos EUA. O legado nacionalista, protecionista e de certa independência da diplomacia mexicana em relação aos EUA foi substituído por uma estratégia de aliado preferencial dos norte-americanos nas questões econômicas, que foi divulgada como a entrada do México no primeiro mundo. Como nas palavras do próprio Carlos Salinas, na ocasião de inauguração do acordo: "Com o tratado de livre comércio com os EUA e o Canadá estaremos nos globalizando e isto é a chave para o ingresso do México no primeiro mundo" (SALINAS apud SAXE-FERNÁNDEZ, 2002: 124). A esperança das elites mexicanas era de que o acordo pudesse facilitar a entrada de capitais estrangeiros que utilizassem o país como base tecnológica e produtiva para as exportaçóes aos EUA, dinamizando, dessa forma, o modelo econômico exportador. A opção por essa nova orientação econômica decorreu de um quadro de crise terminal do modelo de substituição de importações que, com a majoração das taxas de juros nos países centrais, o enxugamento do mercado mundial de capitais e a queda dos preços das exportaçóes de produtos primários, acabou se traduzindo numa grande dívida externa pública e, por conseqüência, na falência fiscal do Estado. A crise econômica e social proveniente do endividamento externo, bem como o desperdício, a ineficiência e a corrupção presente nos aparelhos estatais também contribuíram para essa mudança de estratégia econômica. Além, claro, do fato de que o mercado dos EUA respondia por cerca de $65 \%$ do comércio exterior mexicano.

Para os EUA, o México constitui um país estratégico por uma série de razões que estão relacionadas às suas questôes de segurança, devido à imensa fronteira entre os dois países, aos seus interesses geoeconômicos, ligados aos recursos naturais mexicanos e às suas estratégias geopolíticas para a América Latina. Sob vários aspectos pode-se dizer que as pretensões dos EUA com a adesão do México ao Nafta envolveram todas essas dimensóes citadas. Com o acordo, os EUA esperavam institucionalizar as reformas orientadas para o mercado; assegurar condições mais abertas e seguras para seus investidores e sua propriedade intelectual; garantir o seu abastecimento energético a bons preços; obter a cumplicidade do México nas suas políticas de combate à imigração ilegal e ao tráfico de drogas; e ter o México como exemplo e aliado para avançar no processo de integração econômica do continente (ALCA), diante de um contexto de intensa rivalidade intercapitalista com os asiáticos e os europeus (MARGÁIN, 1995; CORONADO, 2000).

Para tanto, a diplomacia norte-americana não poupou esforços internos e externos para a aprovação do acordo. Nos EUA, a aprovação do tratado - que 
para o vice-presidente Albert Gore "era tão importante quanto a compra da Louisiana e do Alaska" - ocorreu numa votação apertada no Congresso onde acabaram prevalecendo as duras pressóes do poder executivo, das corporações e dos financistas, a despeito da oposição popular, dos sindicatos e da própria agência de pesquisa do Congresso (Office of Technology Assessment), que chamavam a atenção para os termos do acordo e os seus possíveis impactos negativos sobre os trabalhadores e o meio ambiente. No México, além de contar com o importante papel cumprido pelo FMI e pelo Banco Mundial no processo de reformas para o mercado no país, a diplomacia dos EUA também utilizou os serviços da USIA (United States Information Agency) na campanha pró-Nafta. Essa agência oficial de propaganda do governo norte-americano - que após o fim da guerra fria foi integrada ao Departamento de Estado e trocou o discurso anticomunista pela nova ofensiva do governo Clinton de promover a expansão dos interesses financistas e comerciais dos EUA no exterior - cumpriu um importante papel no processo de garantir a adesão de determinados segmentos da sociedade mexicana ao tratado. Um fragmento do relatório interno da USIA, denominado "USIA and Nafta: Building a Foundation for Success" demonstra bem o papel do órgão no processo de implementação do Nafta:

Trabalhamos para mostrar aos segmentos mais influentes da sociedade mexicana que os interesses dos Estados Unidos no México eram muito mais profundos do que meras margens de lucro. Alimentando o interesse e respeito americano pelos valores $\mathrm{e}$ cometimentos intelectuais e culturais mexicanos, pudemos construir uma base social para a cooperação econômica e política ao mesmo tempo em que desarmávamos a maior oposição potencial do México ao Nafta (Apud SNOW, 2004: 66).

Para a ex-pesquisadora da agência, Nancy Snow (2004: 66):

A edificação dessa base social foi facilitada pelo fato de que o então Presidente Salinas, seis de seus ministros e seus três principais negociadores na questão do Nafta haviam recebido treinamento e educação nos Estados Unidos, muitos à sombra do programa da Fulbright patrocinado pela USIA.

Sem a pretensão de fazer uma análise detalhada do tratado e de todos os seus efeitos, que certamente demandariam novos trabalhos, procuraremos apenas constatar pontos importantes que se referem aos grandes objetivos da política externa dos EUA para o México, conforme já enunciado. Um desses aspectos centrais está relacionado ao empenho da diplomacia norte-americana no sentido de garantir o acesso de seu grande capital aos recursos naturais, à força de trabalho e ao capital de outras nações e, ao mesmo tempo, protegê-lo do controle político e democrático das sociedades. Quando observamos alguns capítulos e artigos do Nafta, parece evidente que o tratado pretendeu institucionalizar reformas que garantissem essas diretrizes. 
Os capítulos XI, XIV, XIX e XX do Nafta contêm uma série de disposições jurídicas supranacionais que protegem a mobilidade do capital e do comércio na América do Norte. O Capítulo 11, cujo conhecimento público só ocorreu depois da ratificação do tratado, estabeleceu normas sobre os investimentos externos dos três países, que conferiram direitos, garantias e vantagens importantes para o trânsito desses investidores dentro da área de livre comércio. Um leitor menos atento poderia afirmar que o estabelecimento de regras comerciais que protejam investidores é algo peculiar a qualquer tratado de livre comércio. Porém, as disposiçôes do capítulo 11 vão além dessa questão, na medida em que concedem aos investidores estrangeiros determinados privilégios que sobrepõem e anulam as legislações nacionais, prevendo inclusive punições a qualquer tipo de intervenção jurídica ou política nacional que lese a livre ação desses investidores. $\mathrm{O}$ artigo 1110, do capítulo 11, por exemplo, obriga os Estados-membros a indenizarem os investidores estrangeiros em situações nas quais as decisões soberanas das autoridades nacionais sejam consideradas "equivalentes a uma expropriação". $\mathrm{O}$ artigo 1106, do mesmo capítulo, por sua vez, tira dos Estados nacionais o direito de impor "determinados requisitos ou exigências de comportamento" aos investidores, como aceitar uma determinada porcentagem de conteúdo local ou nacional na produção ou na contratação de empregados. $\mathrm{O}$ artigo 1102 obriga os Estados nacionais a oferecerem "o mesmo tratamento aos investidores externos provenientes do Nafta que o dado aos investidores nacionais nas mesmas circunstâncias". O artigo 1109 assinala que todos os ganhos e dividendos derivados de investimentos de alguma das partes, gozarão de liberdade irrestrita para sua transferência. Além disso, o mecanismo de solução de controvérsias do capítulo 11 marginaliza as normas jurídicas dos países ao introduzir a arbitragem de leis internacionais de comércio privado. ${ }^{1}$ Isto significa que, quando uma empresa move uma ação contra qualquer governo membro do tratado sob a alegação de uma violação de seus direitos de investidor, a solução fica submetida à arbitragem de leis internacionais, que, muitas vezes, estão completamente desvinculadas da legislação e das necessidades locais. Cabe lembrar que o Nafta é um acordo de caráter mercantil, exclusivamente centrado no intercâmbio de bens e mercadorias. Nesse sentido, não foram criadas instituições supranacionais que pudessem regular a aplicação desses capítulos.

Um dos efeitos práticos dessa legislação tem sido o desencadeamento de vários processos de empresas estrangeiras contra políticas estatais nos tribunais criados pelo Centro Internacional de Ajuste de Disputas em Matéria de Investimentos (CIADI) e pela Regras de Arbitragem da Comissão das Nações Unidas sobre Direito Mercantil Internacional (UNCITRAL). No México, em 1997, a empresa norte-americana Metalclad Corp. entrou com um pedido de indenização de US\$ 90 milhões contra o Estado mexicano, após o governo municipal de Guadalcázar

1 North American Free Trade Agreement, 1994. 
cancelar a instalação de um depósito de resíduos tóxicos que comprovadamente vinha contaminando a água da região e o Estado de San Luis Potosí ter declarado o local como zona ecológica. A empresa alegou que as leis de zoneamento prejudicaram seus negócios. Em agosto de 2000, um tribunal do CIADI obrigou o governo mexicano a pagar uma indenização de US\$16,5 milhões à empresa por prejudicar as possibilidades de lucro da mesma (FAZIO, 2001; GUTIÉRREZHACES, 2004).

Ainda nesse país, em abril de 1999, Marvin Roy Feldman, cidadão dos EUA, encaminhou um pedido de indenização de US\$ 50 milhôes contra o Estado mexicano, depois que o governo do México negou à empresa Cemsa (uma companhia estrangeira exportadora de cigarros) os benefícios de uma lei que reembolsava certos impostos aos exportadores. Em 16 de dezembro de 2002, um tribunal do CIADI ordenou ao governo mexicano pagar a Cemsa uma indenização de US\$ 1,5 milhões (GUTIÉRREZ-HACES, 2004). Nos processos movidos pela empresa Waste Management em 1998 e 2000, exigindo uma indenização de US\$ 60 milhôes do governo mexicano pelo cancelamento da concessão de serviços públicos no setor de limpeza, os tribunais do CIADI foram a favor do Estado mexicano nas decisões de 2000 e 2004 (GUTIÉRREZHACES, 2004). No Canadá, em abril de 1997, o parlamento canadense proibiu o uso do aditivo Mmt na gasolina, sob a alegação de que o manganês que se emite na combustão do motor dos automóveis pode afetar a coordenação motora e a memória das pessoas. A empresa dos EUA, Ethyl Corp., que vendia a gasolina com Mmt no país, apoiando-se no capítulo 11 do Nafta, entrou com um pedido de indenização de US $\$ 250$ milhões contra o governo canadense, alegando que a proibição constituía um grave dano para seus interesses financeiros e sua reputação comercial. Punido, o governo canadense teve que negociar um acordo no qual ficava livre do pagamento de indenização a empresa no valor de US\$ 13 milhões e, em compensação, assumia publicamente que o Mmt não representava perigo para a saúde da população (FAZIO, 2001).

Em conjunto, esses artigos acabaram conferindo aos investidores desses países atribuições de sujeito do direito internacional, que, antes do tratado, estavam reservadas exclusivamente aos Estados. Com isso, as empresas transnacionais conquistaram, no âmbito regional da América do Norte, determinadas prerrogativas que não conseguiram impor na esfera mundial, apesar de todos os esforços do governo Clinton no sentido de aprovar o Acordo Multilateral de Investimentos (AMI), que fracassou devido às resistências nacionais e sociais pelo mundo todo.

Pode-se dizer que o interesse maior das grandes corporações nesse tipo de legislação não é a questão da indenização, tanto que a maior parte dos processos contra os Estados têm sido feitos por empresas médias, que, muitas vezes, investem em regiōes envolvidas com questões ambientais, trabalhistas e sociais, esperando que, em algum momento, os poderes públicos se oponham às suas operaçóes para então aproveitar as cláusulas do capítulo XI e buscar indenizações. Para as 
grandes corporações, a questão que está posta é estabelecer normas que possam protegê-las de medidas protecionistas, populares e nacionalistas tomadas por determinados governos, deixando as atividades econômicas dos países ao sabor de seus investimentos.

Do lado da diplomacia dos EUA, o empenho sem concessões para a aprovação desses capítulos e artigos do Nafta, teve o intuito de não somente implementar a agenda de suas corporações em matéria de liberalização comercial e desregulamentação dos investimentos, mas também cumprir uma diretriz de longa data de sua política externa que é impor acordos, políticas e regulamentos comerciais que impeçam os demais países de promover políticas de desenvolvimento sob bases nacionais que possam, no futuro, criar poderosos adversários na competição intercapitalista e interestatal. Esses artigos e capítulos do Nafta pouco levaram em consideração os graus diferentes de desenvolvimento econômico dos países membros. Por exemplo, EUA e Canadá já possuíam um Acordo de Livre Comércio (ALCCEU), que previa disposições em torno da proteção dos investidores e da liberalização dos investimentos. Para o México, país subdesenvolvido, que acabou fazendo várias modificaçôes nas suas leis para adequar-se ao Nafta, incorporar essa legislação significou diminuir a capacidade do Estado de planejar o desenvolvimento econômico nacional (SAXEFERNÁNDEZ, 2002). Aqui, cabe uma pergunta: Qual seria a posição dos EUA no sistema mundial hoje se, ao longo de sua história de desenvolvimento, tivesse adotado legislação semelhante?

Talvez seja por isso que, passada mais de uma década do nascimento do Nafta e duas décadas de reformas para o mercado, não há nenhum indício de que o país possa ingressar no "primeiro mundo", ou mais especificamente no núcleo central do sistema mundial de Estados. A estratégia de abertura econômica - que priorizou a atração de investimentos externos diretos que pudessem dinamizar as exportações e, por conseqüência, promover o desenvolvimento econômico do país - tem se demonstrado um fracasso, sobretudo quando observamos as taxas de crescimento e os indicadores sociais do país. Dito de outra forma pode-se dizer que o incremento dos níveis de exportações, de investimentos externos diretos e de especializaçôes ocorridos depois do tratado não têm significado para o México uma melhor inserção no mundo e muito menos o almejado desenvolvimento.

No que se refere às exportações mexicanas, embora o período 1994-2003 tenha apresentado índices de crescimento, eles foram menores que os verificados no início do processo de abertura da economia no decênio 1984-1993, quando $\mathrm{o}$ tratado ainda não estava em vigor. $\mathrm{O}$ conjunto das exportações totais do México (envolvendo não somente as destinadas aos sócios do Nafta), excluindo o petróleo, cresceu 11,9\% entre 1994 e 2003 enquanto que no período 19841993 o aumento foi de $15,1 \%$. Sendo que as exportaçóes para os EUA, que se multiplicaram por 3,4 após o acordo, foram responsáveis por grande parte desse índice no período 1994-2003. Aliás, ainda que depois da entrada em vigor do 
tratado tenha ocorrido uma multiplicação por 2,3 nas importações provenientes dos EUA, a expansão das exportações mexicanas para esse país promoveram uma inversão no saldo comercial bilateral em favor do México, gerando um superávit de US\$ 41 bilhões em 2003 (SÁNCHEZ, 2004).

Uma breve análise desses números pode revelar em parte a dinâmica que está posta neste modelo de integração. A julgar pelo simples incremento das exportações aos EUA, alguns analistas são levados a deduzir que o acordo foi um sucesso para o México. Porém, existem algumas constataçōes importantes a serem mencionadas nessa questão. Uma delas é o fato de que o Nafta consolidou a tendência pré-existente na economia mexicana de concentração setorial e regional das exportações aos EUA. De acordo com Antonio Gazol Sánchez (2004), 80\% das exportações mexicanas aos EUA está composta por petróleo, vendas da indústria maquiladora, automóveis e autopeças e alguns produtos de origem agropecuária e pesqueira. Todos esses produtos já compunham a pauta de exportação mexicana aos EUA muito antes do tratado, sendo que o consumo de petróleo obedece à demanda do mercado norte-americano; as empresas maquiladoras dos EUA já possuíam tratamento alfandegário especial para exportar ao seu país; e o setor automobilístico já tinha acordo com o governo mexicano para dinamizar as suas exportações. Nesse sentido, à exceção da indústria têxtil que se dinamizou com o tratado, não ocorreu uma diversificação da pauta exportadora mexicana para os EUA.

Certamente isso não ocorreu pelo fato de o México ter mergulhado numa política de reformas para o mercado, estimuladas por Washington, que retirou boa parte da capacidade do Estado de praticar uma política industrial ativa, que pudesse desenvolver outros setores para exportaçóes que compreendessem produtos com maior valor agregado e que exigissem outro perfil da mão-de-obra e outro tipo de assimilação e inovação tecnológicas. Segundo as diretrizes de Washington, bastava o México promover as reformas que os capitais cumpririam o restante. Talvez por isso, as elites dominantes e governantes mexicanas imaginaram que o primeiro mundo estivesse tão perto com a assinatura do tratado. Na prática, o que houve foi uma concentração das atividades exportadoras nas mãos das corporações transnacionais, sobretudo de base norte-americana, que implicou o incremento das importaçóes de bens para compor seus produtos, gerando uma desarticulação de cadeias produtivas e a progressiva separação do setor exportador do resto da economia. Se for certo afirmar que as exportaçóes mexicanas cresceram com a política de abertura e com o Nafta, aumentando inclusive a participação do país nas exportações mundiais de $0,2 \%$ para $2,2 \%$ na década de 90 , o mesmo não pode ser afirmado em relação a sua participação na formação do valor agregado manufatureiro global que decresceu de $1,9 \%$ para $1,2 \%$, exprimindo a desarticulação das cadeias produtivas depois do tratado e a falta de uma política industrial ativa. Sem esquecer que, segundo dados mais recentes, o México tem descido no ranking de competitividade mundial. 
Além disso, com as corporações comandando boa parte das exportações nada garante que o México continue obtendo grandes saldos positivos na sua balança comercial com os EUA, pois basta essas corporações modificarem suas estratégias produtivas para que ocorra uma diminuição dessas exportações e, por conseqüência, uma alteração nos fluxos de comércio, investimentos e emprego. A concorrência das exportações asiáticas aos EUA e a própria transferência de empresas maquiladoras do México para a China são bons exemplos dessa questão. Segundo Rolando Cordera Campos e Leonardo Lomelí Vanegas (2005: 58-59):

As tendências atuais apontam para uma queda nas exportaçōes mexicanas para os Estados Unidos em alguns dos setores que tradicionalmente tinham sido os mais dinâmicos, mas que nos últimos quatro anos se ressentiram da concorrência das exportaçôes asiáticas de manufaturas e componentes. Entre os setores mais afetados, destacam-se os de automóveis, roupas, têxteis de algodão, televisões e equipamento de vídeo, transformadores e geradores, aparelhos elétricos e partes, acessórios para computadores e partes e equipamentos de telecomunicaçôes. Apesar da recuperação da economia norte-americana, as exportaçôes mexicanas para os Estados Unidos cresceram $1,9 \%$ frente a um aumento de $8,5 \%$ na demanda de importações desse país. Se se exclui o petróleo, as compras de produtos mexicanos pelos Estados Unidos, em 2003, foram 2,6 bilhōes de dólares menores do que as registradas no ano 2000 [...] Tudo parece indicar que o que se apresenta é um esgotamento prematuro da estratégia de crescimento baseado na exportação. Além de não ter podido funcionar como locomotiva da economia por sua desarticulação com o sistema produtivo, o setor exportador da economia mexicana baseou sua estratégia em uma combinação que não resiste à competição com os países asiáticos: baixos salários e baixos aumentos de produtividade associados também a baixos níveis de qualificação da força de trabalho e ao baixo componente tecnológico das atividades maquiladoras. Aqueles setores que estão em melhores condiçôes de resistir ao embate exportador asiático são aqueles que contam com maior qualificação e um componente tecnológico maior e mais sofisticado.

Em relação aos investimentos externos diretos no México, à exceção dos procedentes dos EUA, pode-se dizer que o tratado também não representou um aumento vigoroso como se imaginou. Os investimentos não norte-americanos no período 1994-2002 foram de US\$ 35,401 bilhões quase os mesmos ocorridos entre 1984 e 1993 que foram de US\$ 35,343. Dos EUA, desde a entrada em vigor do tratado até 2002 , vieram anualmente em média US\$ 7 bilhões, muito mais do que o verificado no período 1984-1993 que ficou em US\$ 1,9 bilhão (SÁNCHEZ, 2004). Nessa questão, cabe novamente fazer algumas considerações que extrapolem os números. Primeiro que, no contexto das políticas de liberalização e privatização praticadas no México desde a década de 1980, os investimentos estrangeiros produtivos no país foram, em boa parte, feitos na aquisição de empresas estatais e privadas do país. Desse modo, na maioria dos casos, esses 
investimentos não representaram novas bases produtivas e tecnológicas, além de serem responsáveis pela desarticulação de cadeias produtivas nacionais e por aumentarem as remessas de lucros para o exterior. Uma outra consideração a ser feita está relacionada ao fato de que os investimentos estrangeiros desenvolvidos após o tratado contribuíram para aprofundar as diferenças regionais existentes no país entre os pobres Estados do sudeste e os demais onde se concentraram os investimentos (SOLÍS, 2004; SÁNCHEZ, 2004; CAMPOS e VANEGAS, 2005). Os investimentos das maquiladoras no norte transformaram a região numa extensão do espaço econômico dos EUA, contribuindo para a fragmentação econômica do território mexicano, além de aumentar o grau de dependência da economia do país em relação à economia dos EUA. Ainda a respeito dos investimentos externos, sobretudo de base norte-americana, cabe ressaltar que o México vem perdendo atratividade para outras regiōes como a China e Hong Kong, por exemplo. Com o avanço de novos tratados dos EUA com os países da região, talvez essa tendência possa acentuar-se ainda mais.

Pode-se dizer que o modelo de integração previsto pelo Nafta foi mais um elemento do processo de reformas estruturais para o mercado adotado no México nas duas últimas décadas, que contribuiu para consolidar as tendências de diminuição da renda dos trabalhadores, de desestruturação de cadeias produtivas nacionais, de inviabilização de políticas industriais ativas, de destruição de pequenas e médias empresas, de destruição da produção nacional voltada ao mercado interno, de garantia do livre trânsito de corporaçôes transnacionais e de redução da soberania econômica nacional. Seguramente, esperar que o mercado, controlado pelas grandes corporaçóes transnacionais, produza os meios necessários para uma integração regional que fortaleça e desenvolva os espaços nacionais de países periféricos constitui um grande equívoco. Antonio Gazol Sánchez ressalta que:

Passados dez anos e o que fica claro é que nem a consolidação do impulso exportador iniciado antes, nem o aumento dos investimentos externos, nem a especialização têm implicado em maiores taxas de crescimento e melhores condiçôes de vida para os mexicanos. A importância que têm adquirido as remessas de trabalhadores migratórios na balança de pagamentos constitui uma contundente resposta à antiga previsão de 1992-1994 no sentido de que, com o tratado, o México não exportaria pessoas, porque exportaria mercadorias. Se tem exportado mercadorias, tem também exportado pessoas, e muito mais que em 1994 (2004:29).

Para não esquecer, a taxa média anual de crescimento do PIB mexicano após o tratado foi de apenas 2,5\%, nada além dos 2,3\% do período 1984-2003 e muito distante dos índices das décadas de 60 e 70. Para Weisbrot, Rosnick e Baker (2004), o impacto do Nafta para o crescimento do PIB foi muito pequeno, algo em torno de $0,5 \%$ ao ano. Enquanto que o salário mínimo do país ficou 21,34\% inferior ao vigente em 1994 . 


\section{O Plano Puebla-Panamá e o Corredor Biológico Mesoamericano}

No projeto de integração das Américas, a fronteira sul do México e a América Central constituem regiões de grande importância para a geoeconomia norteamericana, devido à localização estratégica e à abundância de recursos, tais como: dois oceanos, extensas costas, uma grande variedade de solos, vastas florestas, uma rica biodiversidade, enorme quantidade de água, jazidas de minérios e hidrocarbonetos. Além disso, essa região é motivo de preocupação para a política de segurança norte-americana por ser um território que vivencia o conflito neozapatista, o tráfico de drogas e de armas e o grande fluxo de migrantes ilegais com destino aos EUA. Por essas razões, o sul-sudeste do México e a América central têm despertado, recentemente, um grande interesse por parte não só do governo norte-americano e suas corporaçôes, mas também do Estado mexicano, do Banco Mundial, do BID e de ONGs dos países centrais, como fica evidente nas seguintes iniciativas: os investimentos do Banco Mundial no projeto denominado Corredor Biológico Mesoamericano (CBM); os tratados de livre comércio como o TLC México-América Central e o CAFTA-DR; e o lançamento pelo governo mexicano do Plano Puebla-Panamá (PPP).

Em 21 de março de 2001, o presidente mexicano Vicente Fox anunciou o Plano Puebla-Panamá, que, segundo o documento oficial constitui um projeto de desenvolvimento sustentável com o objetivo de melhorar o padrão de vida das populações das regiōes dos Estados do sul e sudeste mexicano (Campeche, Chiapas, Guerrero, Oaxaca, Puebla, Quintana Roo, Tabasco, Veracruz e Yucatán) e de sete países da América central (Belize, Costa Rica, El Salvador, Guatemala, Honduras, Nicarágua e Panamá). De acordo com o texto oficial do PPP:

Para a região sul-sudeste do México o Plano Puebla-Panamá centra sua atenção em um conjunto de açōes governamentais selecionadas estrategicamente para atacar de forma direta algumas das causas estruturais do atraso da região, em particular das áreas de desenvolvimento humano, infra-estrutura, mudanças institucionais e regulamentos, e políticas de estado que promovam, incentivem e facilitem os investimentos produtivos privados [...] Os benefícios para as regiōes sul-sudeste do México e América Central são substanciais e os permitem superar o atraso existente, melhorando a qualidade de vida de seus habitantes através de uma maior e melhor educação, um crescimento econômico sustentável, a geração de empregos bem remunerados, a harmonização do desenvolvimento social e humano da população com um aproveitamento eficiente dos recursos e uma expansão e integração comercial (PRESIDÊNCIA DA REPÚBLICA DO MÉXICO, 2001: 4-37).

O plano se concentra em algumas áreas que, segundo os seus idealizadores, dariam um grande impulso econômico à região: agroindústria, biotecnologia, autopeças, turismo sustentável, petroquímica, têxteis e componentes eletrônicos. Para tanto, o PPP prevê a realização de grandes projetos de infra-estrutura física 
envolvendo a construção de rodovias, portos marítimos, redes de transmissão elétrica e de comunicações, termoelétricas, hidrelétricas, oleodutos, gasodutos, ferrovias, aeroportos, etc. Espera-se que o seu financiamento seja feito principalmente pela iniciativa privada de cada nação, os governos federais e estaduais da regiáo, os investidores privados externos, o Banco Interamericano de Desenvolvimento (BID), o Banco Mundial, o Bancomext, o Banco centro-americano de integração econômica, entre outros. Desde o início, o PPP tem contado com a simpatia dos países da América Central e do governo norte-americano, que chegou a prometer ajuda econômica, porém, tem sido alvo constante de críticas de vários setores das sociedades envolvidas, tais como acadêmicos, camponeses, sindicatos e pequenos empresários centro-americanos.

Os analistas do assunto se dividem em duas posições que coincidem em reconhecer que o PPP é parte do projeto de integração econômica das Américas dirigido pelos EUA, projeto em que o México cumpre um papel de importante aliado. Para os seus defensores, o plano pode trazer várias contribuições para a região, tais como: a estabilidade econômica e política, a integração ao mundo desenvolvido e a contenção do fluxo migratório para os EUA (PORTALES, 2003). Enquanto os críticos consideram o projeto uma agressão contra os recursos naturais e os povos da região.

Sob vários aspectos, o plano contempla os interesses geoeconômicos e geopolíticos dos EUA, como chama a atenção Carlos Fazio:

O PPP não é um projeto novo e sua autoria intelectual não está no México, e sim em Washington [...] forma parte de um programa integral que combina o intervencionismo político, econômico e militar, mas se apresenta como um plano de pacificação, desenvolvimento e criação de empregos. É uma manifestação genuína do capitalismo contemporâneo. Forma parte de um projeto de alcance geoestratégico continental e imperial dos EUA, no qual participam setores do capital financeiro, consórcios multinacionais e oligarquias do México e da América Central. O governo de Vicente Fox participa de maneira subordinada aos interesses da Casa Branca, Wall Street e às transnacionais com matriz nos EUA [...] O propósito dos EUA com o PPP é intervir no conflito político e social do México para impor e favorecer as transnacionais do petróleo; facilitar a privatização dos terminais aéreos e portuários, a energia elétrica, a água, o gás e a Pemex; proteger os proprietários de terras empenhados no desenvolvimento agroindustrial e, principalmente, apoderar-se sem restrições das enormes riquezas da biodiversidade da selva da Lacandona, os Chimalapas em Oaxaca e o Corredor biológico Mesoamericano que chega até o Panamá (FAZIO apud DELGADORAMOS, 2004: 94-5).

Visto assim, o PPP é um projeto que visa complementar a integração econômica da regiáo de acordo com os parâmetros estabelecidos pelos EUA e aprofundar a inserção subordinada das economias da região na economia mundial 
colocando à disposição do capital transnacional suas vantagens comparativas que são: localização geográfica, recursos energéticos, mão-de-obra barata e biodiversidade (CHANONA, 2003; PÉREZ, 2003; BELLO, 2002; SOLÍS, 2004; DELGADO-RAMOS, 2004).

Talvez seja por essas razões que o projeto anunciado por Vicente Fox tenha ganhado uma infinidade de inimigos justamente entre aqueles setores sociais que supostamente o PPP espera beneficiar, como os trabalhadores, os indígenas e os camponeses. Afinal, ninguém tem dúvida de que falta infra-estrutura na região, de que as populações dessas regiōes possuem níveis de pobreza e exclusão maiores que os demais Estados do centro e do norte do México, de que os índices de analfabetismo e desistência escolar são altos, de que os níveis de qualificação da mão-de-obra são ínfimos e de que algo precisa ser feito. Porém, cabem algumas perguntas sobre a forma como o PPP pretende de fato contribuir para a resolução desses problemas. Será que desregulamentar o acesso das grandes corporações transnacionais aos recursos naturais e à biodiversidade constitui um caminho para o desenvolvimento, sobretudo num contexto em que as legislaçóes dos acordos comerciais com os EUA procuram defender os direitos de propriedade intelectual e controle de patentes? Será que para o México aprofundar um modelo exportador ligado principalmente às maquilas, que já se mostrou problemático para o seu desenvolvimento, como procuramos apontar no Nafta, significa inserir o país no mundo de uma forma que possa resolver seus graves problemas sociais ou, ao contrário, implica reproduzir o subdesenvolvimento? Mesmo a questão do meio ambiente e o desenvolvimento sustentável. Será que é possível preservar ecossistemas únicos no planeta com a dinâmica de um projeto que prevê a construção de uma infra-estrutura que fragmenta o espaço das reservas mais importantes do Corredor Biológico Mesoamericano, como a biosfera Maya, por exemplo? Essas são questôes importantes para tentar entender para onde essas reformas e projetos podem levar a região. Será que esse é o caminho do desenvolvimento em tempos de globalização?

Após cinco anos do seu lançamento, o PPP caminha de forma lenta, pois poucas obras do plano conseguiram financiamento. Isso se deve a uma série de questôes que devem ser mencionadas. Primeiro que o Estado mexicano perdeu significativamente sua capacidade de financiamento de grandes projetos. Segundo que o governo norte-americano, envolvido em outros problemas e prioridades, não tem fornecido a ajuda econômica prometida. E terceiro que a resistência de uma heterogeneidade de atores sociais, incluindo a ameaça de retomada do conflito por parte do EZLN (Exército Zapatista de Libertação Nacional), tem dificultado a captação de recursos e a implantação dos projetos. Tanto que nas últimas obras de infra-estrutura, aeroportos e rodovias inauguradas no Estado do Chiapas, os governantes não têm mencionado as realizações como pertencentes ao PPP. 
Um outro projeto em curso nas regiões sul-sudeste do México e América Central é o do Corredor Biológico Mesoamericano, que, para muitos estudiosos, constitui juntamente com o Plano Puebla-Panamáe o TLCMéxico-Centroamérica, mais uma iniciativa que complementa a tentativa norte-americana de construir a ALCA. Nesse caso trata-se de um mapeamento da biodiversidade da região, sob o olhar atento das corporaçóes transnacionais.

A iniciativa do "Corredor Biológico Mesoamericano" (CBM) foi formalmente lançada na XIX Cúpula Presidencial Centro-americana, realizada no Panamá, em 12 de junho de 1997, porém teve início somente a partir do ano 2000, quando passou a ser administrado pelo Banco Mundial. Segundo o Banco, o projeto do CBM, que envolve os Estados mexicanos de Campeche, Yucatán, Quintana Roo e Chiapas e os países centro-americanos, dirige-se à conservação da biodiversidade e seu uso com fins econômicos de forma sustentável. Um documento do Banco Mundial sobre o projeto diz que:

A área representa apenas $0,5 \%$ da superfície terrestre total do mundo, porém estimase que contenha $7 \%$ da biodiversidade conhecida do planeta. O programa utiliza a conservação ambiental como um catalisador para reduzir a pobreza e melhorar a qualidade de vida, fomentar a cooperação regional, preservar o rico patrimônio cultural da região e promover uma nova imagem da América Central no mundo (Apud SOLÍS, 2004: 40).

É difícil acreditar que, numa conjuntura na qual os países centrais defendem vigorosamente os direitos de propriedade intelectual e as garantias de patentes de suas corporações, esse tipo de projeto dirigido pelo Banco Mundial possa ter como objetivos fundamentais apenas as justas causas da conservação do meio ambiente e da redução da pobreza. Para Jaime Ornelas Delgado (2003: 44):

Esse programa promovido, financiado e dirigido pelo Banco Mundial compreende conhecer e quantificar os recursos naturais existentes na região para permitir ao capital privado explorá-los em seu exclusivo benefício.

Concordando com essa análise, John Saxe-Fernández e Gian Carlo DelgadoRamos (2005: 76) afirmam:

O Banco Mundial e outros organismos, mediante projetos tipo Corredor Biológico Mesoamericano, estão dando os primeiros passos para construir um sistema de biopirataria continental subordinado aos interesses empresarias dos Estados Unidos e seus aliados europeus.

A favor dessas afirmaçōes podemos citar, por exemplo, o fato de que o Banco Mundial também foi o principal administrador do projeto "Revolução Verde" para o Terceiro Mundo, nos anos 60, e que teve conseqüências desastrosas 
para o meio ambiente, além de ampliar a dependência dos países em relação às corporações transnacionais da agroindústria (SHIVA, 2001). Pode-se dizer que o gerenciamento do projeto CBM pelo Banco Mundial e demais instituições internacionais cria um espaço para que essas agências interfiram nas políticas internas dos países fazendo prevalecer as suas visões de política ambiental, que muitas vezes podem estar sintonizadas com os interesses dos países centrais e de suas corporações e, por conseqüência, distantes dos anseios dos povos e da sustentabilidade ecológica.

Para vários analistas, o Corredor Biológico Mesoamericano tem uma relação íntima com o Plano Puebla-Panamá, sobretudo no que se refere às questôes do aproveitamento da biodiversidade pelas corporações transnacionais, principalmente de base norte-americana. Como nas palavras de Gian Carlo Delgado-Ramos (2004: 187):

Sem dúvida alguma, o CBM não é outra coisa que a "versão verde" do Plano Puebla-Panamá que busca colocar os recursos mesoamericanos nas mãos dos atores estrangeiros.

Com as iniciativas do Plano Puebla-Panamá, do Corredor Biológico Mesoamericano e do TLC México-América Central, pode-se dizer que, ainda que de forma lenta, vem ocorrendo uma tentativa de reconfiguração das regióes sul-sudeste do México e América Central em plena sintonia com os objetivos centrais do projeto norte-americano de integração econômica das Américas. Nesse processo, como tentamos demonstrar, os caminhos econômicos adotados pelas elites governantes do México, nas últimas duas décadas, têm sido decisivos.

\section{Recebido em 23 de novembro de 2006 Aprovado em 5 de maio de 2007}

\section{Bibliografia}

BELLO, L. M. R. "México- gran Caribe: ¿Colaboración o competencia?” In: OLIVA, C., SERBIN, A. (Coords.) América Latin, el Caribe y cuba en el contexto global. AraraquaraUNESP, FCL, Laboratorio Editorial; Havana: AUNA, 2002, p. 142-168.

CAMPOS, R. C. VANEGAS, L. L. "Avaliação das mudanças estruturais no México (19822004)”. In: DUPAS. G. (Coord.) América Latina no início do século XXI: perspectivas econômicas, sociais e políticas. Rio de Janeiro: Fundação Konrad Adenauer; São Paulo: Fundação Editora da Unesp, 2005, p. 39-74.

CHANONA, A. "Procesos de integración en el marco Del Plan Puebla-Panamá (PPP)". In: FORERO, E. A. S., PÉREZ, R. S (Coords.). Lectura crítica del Plan Puebla Panamá. Estados Unidos: Libros en Red.com, 2003, p. 55-74. 
CORONADO, J. P. “La geopolítica de las relaciones entre México y Estados Unidos”. In: Cenários. Revista do Grupo de Estudos Interdisciplinares sobre Cultura e Desenvolvimento. n. 2, 2000, p. 78-94.

DELGADO, J. O. "El Plan Puebla Panamá y la globalización neoliberal”. In: FORERO, E. A. S., PÉREZ, R. S (Coord.). Lectura crítica del Plan Puebla Panamá. Estados Unidos: Libros en Red.com, 2003, p. 19-54.

DELGADO-RAMOS, G. C. Biodiversidad, desarrollo sustentable y militarización: esquemas de saqueo en Mesoamérica. México: Plaza y Valdes editores, 2004.

GUTIÉRREZ-HACES, T. "La inversión extranjera directa en el TLCAN.” Economía UNAM, Universidad Autónoma de México n.3, set.-dez. 2004, p. 30-52.

MARGÁIN, E. Los intereses, el poder y a distribución del ingreso en relaciones internacionales altamente asimétricas: El Tratado de Libre Comercio y la crisis del neoliberalismo mexicano. México: Universidad Nacional Autónoma de México, 1995.

NORTH AMERICAN FREE TRADE AGREEMENT. Washington, D.C: U.S. Government Printing Office, 1994.

PÉREZ, R. S. "El vínculo militar Del Plan Colombia y el Plan Puebla Panamá”. In: FORERO, E. A. S., PÉREZ, R. S (Coord.). Lectura crítica del Plan Puebla Panamá. Estados Unidos: Libros en Red.com, 2003, p. 9-18.

PLAN PUEBLA PANAMÁ. Presidencia de la República, Documento Base, México, 2001.

PORTALES, C. “¿Tiene México viabilidad sin los Estados Unidos?”. Estudios Internacionales. Universidad de Chile. n. 141, abril-junho 2003, p. 91-108.

SÁNCHEZ, A. G. “Diez años del TLCAN: una visión al futuro". Economía UNAM. Universidad Autónoma de México. n. 3, set.-dez. 2004, p. 9-29.

SAXE-FERNÁNDEZ, J. La compra-venta de México. Una interpretación histórica y estratégica de las relaciones México-Estados Unidos. México:Plaza Janés, 2002.

SAXE-FERNÁNDEZ, J., DELGADO-RAMOS, G. C. Imperialismo económico en México: las operaciones del Banco Mundial en nuestro país. México: Arena Abierta, 2005.

SNOW, N. Propaganda, Inc.: vendendo ao mundo a cultura dos Estados Unidos. Rio de Janeiro: Graphia, 2004.

SOLÍS, D. V. La frontera sur de México: del TLC México-Centroamérica al Plan PueblaPanamá. México: Plaza y Valdes Editores México, 2004.

SHIVA, V. Biopirataria: a pilhagem da natureza e do conhecimento. Petrópolis, RJ: Vozes, 2001.

TAMBURINI, F. "Historia y destine de la "Doctrina Calvo": ¿Actualidad u obsolescencia del pensamiento de Carlos Calvo?” Revista de Estudios Histórico-jurídicos, n. 24, Valparaiso, 2002, p. 81-101.

TWOMEY, M. J. Las corporaciones multinacionales y el Tratado de Libre Comercio de América del Norte. México: Fondo de Cultura Económica, 1996.

WEISBROT, M., ROSNICK. D., BAKER, D. “Diez años del TLCAN: el recuento”. Economía UNAM, Universidad Autónoma de México n. 3, set.-dez. 2004, p. 53-61. 


\section{Resumo}

O artigo sugere que, nas duas últimas décadas, os governos mexicanos vêm adotando medidas políticas e econômicas amplamente afinadas com o modelo de integração econômica das Américas proposto pelos EUA. A adesão incondicional ao Nafta e o empenho para consolidar os projetos do Corredor Biológico Mesoamericano e do Plano Puebla-Panamá são exemplos fundamentais dessa estratégia.

\section{Abstract}

The article suggests that, during the two last decades, the Mexican government has been adopting political and economic measures in tune with the economic integration model for the Americas proposed by the United States of America. Examples of this strategy are the unrestricted entry into North-American Free Trade Agreement (Nafta) and the effort to consolidate the projects for a Mesoamerican Biological Corridor and the Puebla-Panamá Plan.

Palavras-chave: EUA, México, Integração econômica.

Key-words: USA, Mexico, Economic union. 